DE BARROS LEAL, Mayka Marques Paes. As tragédias socioambientais no brasil: a emergência da responsabilização das empresas mineradoras frente à violação dos direitos humanos. Revista Eletrônica Direito e Política, Programa de Pós-Graduação Stricto Sensu em Ciência Jurídica da UNIVALI, Itajaí, v.16, n.1, $1^{\circ}$ quadrimestre de 2021. Disponível em: www.univali.br/direitoepolitica - ISSN 1980-7791

\title{
AS TRAGÉDIAS SOCIOAMBIENTAIS NO BRASIL: A EMERGÊNCIA DA RESPONSABILIZAÇÃO DAS EMPRESAS MINERADORAS FRENTE À VIOLAÇÃO DOS DIREITOS HUMANOS
}

\author{
THE SOCIOENVIRONMENTAL TRAGEDIES IN BRAZIL: THE EMERGENCY \\ OF LIABILITY OF MINING COMPANIES FOR HUMAN RIGHTS VIOLATIONS
}

Mayka Marques Paes de Barros Leal ${ }^{1}$

\begin{abstract}
RESUMO
O presente artigo analisa as violações aos direitos humanos provocados pelas mineradoras proprietárias das barragens de Mariana e Brumadinho e demonstra a necessidade de responsabilização das empresas inclusive no âmbito internacional. Para tanto se faz necessário, primeiramente, abordar qual foi a dimensão da tragédia em Mariana, esclarecendo quais foram as medidas recomendadas e tomadas que se mostrarem insuficientes para evitar que uma nova tragédia ocorresse em Brumadinho de dimensões ainda maiores quando olhamos a morbidade. Será demonstrado que em ambas as tragédias fora afastado por parte da empresa exploradora de minérios, no que tange a indenização, o principio da centralidade do sofrimento da vítima. Depois, será defendido a necessidade de superação do paradigma estatocêntrico, responsabilizando as empresas transnacionais e o Estado, solidariamente, para que haja uma efetiva proteção aos direitos humanos. A metodologia utilizada foi pesquisa bibliográfica, com utilização de artigos e livros publicados.
\end{abstract}

PALAVRAS-CHAVE: Direitos Humanos; Empresas mineradoras; Responsabilidade Internacional; Mariana; Brumadinho.

\section{ABSTRACT}

This article analyses the human rights violations caused by mining companies of Mariana's and Brumadinho's dam and shows the need of companies' liability including internacional scope. At first, it is necessary to approach the dimension of the tragedy in Mariana, clarifying the recommended and taken actions that were inadequate to avoid that a new disaster happened in Brumadinho, a bigger disaster in terms of morbidity. It will be demonstrated that in both tragedies were removed the centrality principle of victims' suffering by the mining companies, in relation to the indemnity. Afterwards, it will be defended the need for overcoming the statecentred paradigma taking full responsability of transnational companies and the State, severally liable, to provide an efective protection to the human rights.

\footnotetext{
1 Mestranda em Direito pela Universidade Federal de Mato Grosso (UFMT). Especialista em Direito Tributário pela Pontifícia Universidade Católica de São Paulo (PUCSP). Advogada. E-mail: maykampbarros@gmail.com
} 
DE BARROS LEAL, Mayka Marques Paes. As tragédias socioambientais no brasil: a emergência da responsabilização das empresas mineradoras frente à violação dos direitos humanos. Revista Eletrônica Direito e Política, Programa de Pós-Graduação Stricto Sensu em Ciência Jurídica da UNIVALI, Itajaí, v.16, n.1, $1^{\circ}$ quadrimestre de 2021. Disponível em: www.univali.br/direitoepolitica - ISSN 1980-7791

The methodology used was bibliographic research, using published articles and books.

KEY-WORDS: Human rights; mining companies; International responsability; Mariana; Brumadinho.

\section{INTRODUÇÃo}

O presente artigo tem o intento de olharmos as tragédias socioambientais que ocorreram recentemente em Mariana e Brumadinho com foco nas flagrantes violações aos Direitos Humanos ali cometidos, que nos fez perceber que é urgente que haja a responsabilização das empresas transnacionais de mineração.

Salientamos que embora consideramos o meio ambiente como direito humano, por vezes, neste artigo, iremos enfatiza-lo de forma separada a vidas humanas, devido as tragédias salutares serão tratadas.

É importante frisar que o objetivo desse artigo passa longe de querer criminalizar, ou tem o intento de se insurgir sobre as empresas mineradoras ${ }^{2}$, sabemos da importância econômica de atividades como essa e a importância de uma economia forte para uma nação, contudo, frisamos que nunca se devem mitigar os direitos humanos em prol de qualquer crescimento e fortalecimento de Estados e /ou empresas.

Para tanto, na primeira parte, daremos ênfase nas tragédias, primeiramente, respeitando a cronologia, de Mariana e, posteriormente, de Brumadinho, tentando demonstrar em palavras as grandes violações aos direitos humanos e ao meio ambiente que ocorreram devido aos rompimentos das barragens.

Na segunda parte, procuraremos, entender como a relação empresas e direitos humanos têm sido observada internacionalmente e se estamos caminhando ou

\footnotetext{
2 Até porque, apesar dos riscos ambientais, a mineração deve ser tolerada em virtude da amplitude de usos dados a esses recursos em várias áreas do cotidiano das pessoas e nas indústrias e nas pesquisas.
} 
DE BARROS LEAL, Mayka Marques Paes. As tragédias socioambientais no brasil: a emergência da responsabilização das empresas mineradoras frente à violação dos direitos humanos. Revista Eletrônica Direito e Política, Programa de Pós-Graduação Stricto Sensu em Ciência Jurídica da UNIVALI, Itajaí, v.16, n.1, $1^{\circ}$ quadrimestre de 2021. Disponível em: www.univali.br/direitoepolitica - ISSN 1980-7791

não para uma responsabilização dessas empresas, que hoje parece não ser possível no âmbito internacional.

Com isso, mostraremos ao leitor que embora não se tem julgados e entendimentos das cortes internacionais (aqui enfatizaremos o Sistema Interamericano de Direitos Humanos) no sentido de responsabilização das empresas, o que temos, consolidado é que os Estados são responsáveis pela fiscalização das empresas em seu território e que tem se buscado há algum tempo uma forma de comprometimento dessas com os direitos humanos e há algum esforço para se tentar elaborar um tratado que torne esse comprometimento norma jurídica internacional.

A metodologia utilizada para a elaboração do artigo foi pesquisa bibliográfica, com utilização de artigos e livros publicados, de matérias de jornais e revistas e relatórios acerca das tragédias socioambientais objeto desse artigo.

\section{EMPRESAS TRANSNACIONAIS DE MINERAÇÃO COMO PROTAGONISTAS DE GRANDES VIOLAÇÕES DOS DIREITOS HUMANOS EM SOLO BRASILEIRO}

Com a globalização econômica que teve início na década de 1970, empresas de todo mundo passaram a ampliar suas atividades, saindo de seu Estado de origem e se instalando em outros Estados. Preocupação recente do Direito Internacional tem sido investigar o papel das empresas na promoção e proteção dos direitos humanos, bem como suas responsabilidades. ${ }^{3}$

Quando falamos de empresas extrativistas, esta promoção e proteção aos direitos humanos devem ser mais intensas, haja vista que a própria natureza do empreendimento modifica o local explorado e acaba por trazer consequências ambientais e sociais.

\footnotetext{
3 MAZZUOLI, Valerio de Oliveira. Curso de Direitos Humanos. 6aed., atual. e ampl. Rio de Janeiro: Forense; São Paulo: Método,2019. p.547.
} 
DE BARROS LEAL, Mayka Marques Paes. As tragédias socioambientais no brasil: a emergência da responsabilização das empresas mineradoras frente à violação dos direitos humanos. Revista Eletrônica Direito e Política, Programa de Pós-Graduação Stricto Sensu em Ciência Jurídica da UNIVALI, Itajaí, v.16, n.1, $1^{\circ}$ quadrimestre de 2021. Disponível em: www.univali.br/direitoepolitica - ISSN 1980-7791

No Brasil a exploração acontece há mais de 300 anos, mas nos últimos 15 anos houve uma intensificação da exploração de diversos minerais, impulsionado pela demanda internacional, esse período foi classificado com um boom ou superciclo das commodites. ${ }^{4}$ No entanto, parece-nos, que esse boom não foi acompanhado com os cuidados devidos com os direitos humanos e com o meio ambiente.

Infelizmente, conforme a história e os últimos acontecimentos tem nos mostrado, as violações aos direitos humanos pelas empresas de minerações, com capital e direção na maioria das vezes transnacionais, tem sido cada vez mais explícito e pouco punido, dentro e fora do Estado brasileiro. Governos e empresas juntos parecem preferir mais os lucros e crescimento econômico local ao invés de visar as proteções dos direitos humanos como um todo.

Vamos demonstrar ao longo desse artigo que internamente o Estado brasileiro não conseguiu impedir que tais violações ocorressem, bem como, não tem conseguido repara-las de forma efetiva.

Quando olhamos para os casos que iremos abordar neste artigo, Mariana e Brumadinho vemos que a barragem de Fundão, localizado em Mariana-MG, é de propriedade da Samarco que é uma empresa de capital fechado, controlados por duas acionistas: a Vale S.A e BHP Billiton Brasil Ltda, sendo a Vale empresa brasileira e a BHP empresa anglo-australiana. Salientamos que desde o século XXI, essas duas empresas do mercado de minério de ferro mundial, fazem parte das três gigantes do setor mineral que controlam o mercado e impõem leis onde estão situados e que atuam. ${ }^{5}$

Fixadas essas premissas, esta primeira parte falará do que foram essas duas tragédias decorrentes de rompimento de barragem em Minas Gerais, apontando algumas violações ao meio ambiente e aos direitos humanos.

\footnotetext{
4 ANDRADE, Maria Julia Gomes; SILVA, Jarbas Oliveira da. Introdução. In: MILANEZ, Bruno; LOSEKANN, Cristina (org.). Desastre no Vale do Rio Doce: antecedentes, impactos e ações sobre a destruição. Rio de Janeiro: Folio Digital: Letra e Imagem, 2016.p.24

5 LOPES, R. Caso do desastre socioambiental da Samarco: os desafios para a responsabilização de empresas por violações de direitos humanos. In: MILANEZ, B.; LOSEKANN, C. 2016. Desastre no vale do Rio Doce: antecedentes, impactos e ações sobre a destruição. Rio de Janeiro: Ed. Folio Digital: Letra e imagem, 2016, p. 373.
} 
DE BARROS LEAL, Mayka Marques Paes. As tragédias socioambientais no brasil: a emergência da responsabilização das empresas mineradoras frente à violação dos direitos humanos. Revista Eletrônica Direito e Política, Programa de Pós-Graduação Stricto Sensu em Ciência Jurídica da UNIVALI, Itajaí, v.16, n.1, $1^{\circ}$ quadrimestre de 2021. Disponível em: www.univali.br/direitoepolitica - ISSN 1980-7791

\subsection{Caso Mariana: o maior acidente mundial com barragens em 100 anos}

O laudo técnico do IBAMA de novembro de 2015, nos da ideia do tamanho do desastre, consta que em 05/11/2015 ocorreu o rompimento da barragem que continha ferro e manganês, com 50 milhões de metros cúbicos de rejeitos, sendo que de imediato 33 milhões foram lançados no meio ambiente, boa parte percorrendo o Rio Doce e chegando até o Estado do Espirito Santo até serem lançados no Oceano Atlântico.

O laudo ainda aponta que houve mortes de pessoas, de vida aquática e da flora e fauna da região, alteração na água do rio, desalojamento de pessoas, interferência na comunidade indígena, bem como interferência em fornecimento de energia e água potável, ainda trouxe problemas econômicos para a população como os pescadores que não puderam mais pescar nem sequer para sua subsistência, entre outros. A ação Civil Publica movida pela União, Estado de Minas Gerais e Estado do Espírito Santo, elencam pelo menos vinte danos socioambientais decorrentes do rompimento da barragem. Ainda o laudo classifica o desastre de muito grande porte.

A mídia nacional e internacional colocaram o evento catastrófico como o maior acidente mundial com barragens em 100 anos e os seus efeitos sofre-se até hoje.

\subsubsection{O direito a informação amplamente violado.}

Em vários artigos e noticiários, o que vimos sendo explicitamente violado é o direito a informação das pessoas, principalmente daquelas diretamente $e$ indiretamente afetadas.

Erica Mariosa Moreira Carneiro fez uma linha do tempo ${ }^{6}$ descrevendo as primeiras 26 horas, dizendo que as $12 \mathrm{~h}$ alguns funcionários sentiram tremores na empresa, mas foram orientados que era normal e que voltassem a trabalhar normalmente, segundo o engenheiro responsável, foi feita vistoria e não constataram nenhuma

6 CARNEIRO, Erica Mariosa Moreira. Linha do tempo: as primeiras 26 horas. In: CALDAS, Graças (org.) Vozes e silenciamentos em Mariana: crime ou desastre ambiental. 2.ed. Campinas: Unicamp,2017.p.76-100. 
DE BARROS LEAL, Mayka Marques Paes. As tragédias socioambientais no brasil: a emergência da responsabilização das empresas mineradoras frente à violação dos direitos humanos. Revista Eletrônica Direito e Política, Programa de Pós-Graduação Stricto Sensu em Ciência Jurídica da UNIVALI, Itajaí, v.16, n.1, $1^{\circ}$ quadrimestre de 2021. Disponível em: www.univali.br/direitoepolitica - ISSN 1980-7791

irregularidade; as 15:30h uma moradora de moto que avisou aos gritos moradores que a lama estava descendo; $16: 49 \mathrm{~h}$ um portal da Minas gerais divulga a noticia de rompimento da barragem. As 17:45h a prefeitura da cidade emite nota pedindo que os moradores evacuassem a área imediatamente; as 18:02h a Samarco não confirmava o rompimento da barragem; somente as $18: 27 \mathrm{~h}$ a Samarco admite o rompimento da barragem e informa que estava tomando providências; as 22:12 moradores ainda se recusavam a sair de suas casas, pois não conseguiam vislumbrar o tamanho da tragédia; as 09:26 a lama começa atingir cidades vizinhas; $11: 34 \mathrm{~h}$ a Lama chega ao Rio Doce; as 15:08h a empresa diz em entrevista coletiva que a lama não era tóxica.

Vemos que nem o Governo nem a empresa informaram de imediato os riscos e possíveis danos que os rejeitos possuíam e que podiam atingir. A empresa se manifestou à imprensa se defendendo explicando que não havia aviso sonoros porque a lei não exigia, dizendo que as pessoas teriam sido avisadas por telefone, contudo, pelos relatos colhidos, os que souberam foi devido a insistência de moradores gritando e avisando uns aos outros ${ }^{7}$.

As pessoas puderem ter a real dimensão do ocorrido somente após três semanas do rompimento das barragens.

Houve grandes falhas nos planos de contingências e as áreas que potencialmente poderiam ser atingidas não receberam qualquer informação e assim não puderam planejar formas de prevenção.

Os atingidos não tinham posicionamento da empresa. Ninguém da comunidade próxima, na dimensão da extensão que os rejeitos poderiam atingir, teve qualquer tipo de treinamento que os indicasse um caminho a seguir em caso semelhantes.

7 RECORD MINAS. Moradora heroína salvou família e voltou para alertar vizinhos sobre tragédia. Disponível em: https://noticias.r7.com/minas-gerais/moradora-heroina-salvou-familiae-voltou-para-alertar-vizinhos-sobre-tragedia-12112015 
DE BARROS LEAL, Mayka Marques Paes. As tragédias socioambientais no brasil: a emergência da responsabilização das empresas mineradoras frente à violação dos direitos humanos. Revista Eletrônica Direito e Política, Programa de Pós-Graduação Stricto Sensu em Ciência Jurídica da UNIVALI, Itajaí, v.16, n.1, $1^{\circ}$ quadrimestre de 2021. Disponível em: www.univali.br/direitoepolitica - ISSN 1980-7791

Claramente vemos que o direito a informação, que a nosso ver é um direito humano, não foi respeitado, o que viola o direito do homem a ter ciência do que vem acontecendo, não podem negar a população o acesso a informações.

\subsubsection{A denúncia perante o CIDH e o não esgotamento das vias internas}

Se olharmos a jurisprudência da Corte Interamericana de Direitos Humanos vemos que não há caso semelhantes com Mariana que geraram punições. A corte tem se manifestado em casos socioambientais que envolvem sobretudo comunidades indígenas e quilombolas, como o Caso Yanomami de $1985,{ }^{8}$ mas não tem decisões que destaquem de violação dos direitos humanos e do meio ambiente ou sobre mineração, mesmo sendo esta atividade tendo um grande potencial de violações e não tendo qualquer impedimento para atuação nesse sentido. ${ }^{9}$

Quanto a responsabilização das empresas, independentemente da atividade econômica desenvolvida, a Corte Internacional de Direitos Humanos até reconhece que muitas das vezes as violações aos direitos humanos tem origem em agentes não- estatais, contudo, não podem ser estes responsabilizados. ${ }^{10}$

Ainda, a Opinião Consultiva no 22/16, que aduz sobre a titularidade de direitos das pessoas jurídicas no sistema interamericano de direitos humanos, entendeu expressamente que no art.12 da Convenção é claro que as pessoas jurídicas não são titulares de direitos convencionais, pelo que também não podem figurar como vítimas nos processos contenciosos do Sistema Interamericano. ${ }^{11}$ Nesse sentido, entendemos, que se as empresas sequer podem ocupar o polo ativo de casos perante o $\mathrm{CIDH}$, muito menos poderão figurar como polo passivo, ou seja

\footnotetext{
8 Alegou-se que as atividades privadas de extração de minerais afetavam vários direitos desse povo indígena em território brasileiro.

9 YARZA, Fernando Simón. Medio ambiente y derechos fundamentales. Madrid: Tribunal Constitucional y Centro de Estudios Políticos y Constitucionales, 2012. p. 25

10 Exemplo seria o caso Pueblos Kaliña y Lokono Vs. Suriname, onde se reconheceu que as violações foram causadas por atores privados, todavia, referindo-se aos Principios Ruggie, a Corte entendeu ser responsável internacionalmente perante o SIDH, não as empresas envolvidas, mas o Estado Surinamês. ( decisão de 25 de novembro de 2015 da CIDH)

${ }^{11}$ MAZUOLLI, Valério.Direitos humanos na jurisprudência internacional: sentenças, opiniões consultivas, decisões e relatórios internacionais. Rio de Janeiro: Forense; São Paulo: Método, 2019. p.775
} 
DE BARROS LEAL, Mayka Marques Paes. As tragédias socioambientais no brasil: a emergência da responsabilização das empresas mineradoras frente à violação dos direitos humanos. Revista Eletrônica Direito e Política, Programa de Pós-Graduação Stricto Sensu em Ciência Jurídica da UNIVALI, Itajaí, v.16, n.1, $1^{\circ}$ quadrimestre de 2021. Disponível em: www.univali.br/direitoepolitica - ISSN 1980-7791

desprovidos de direitos e deveres perante o Sistema Interamericano de Direitos Humanos. ${ }^{12}$

Mesmo, diante desse cenário pouco favorável para responsabilização das empresas, e sem o esgotamento dos recursos internos ${ }^{13}$, com base nos dados de Mariana e com dados referentes a outras atividades mineradoras no Brasil, várias organizações da sociedade civil ${ }^{14}$ se juntaram e encaminharam uma denuncia a $\mathrm{CIDH}$, demonstrando que há inúmeras violações aos direitos humanos e ao meio ambiente por parte das mineradoras, dos governos e do poder legislativo que tenta com projetos de leis enfraquecer o licenciamento ambiental. Após esse encaminhamento não há no site da Comissão nenhum aceite ou andamento do pedido. ${ }^{15}$

Contudo, a CIDH esteve no Brasil no final de 2018, a convite do próprio Estado Brasileiro e visitou alguns locais e pessoas afim da verificarem a situação dos direitos humanos no Brasil. Em dois parágrafos a CIDH discorre sobre o caso de Mariana e recomenda ao Estado Brasileiro a observância dos direitos humanos e da reparação, mas nenhuma recomendação objetiva quanto a mineração brasileira. ${ }^{16}$

12 GIANNATTASIO, Arthur Roberto Capella; NOGUEIRA, Clara Soares; BISCAIA, Bruno Simões. PIOVESAN, Flávia; SOARES, Inês Virgínia $P_{1}$; TORELLY, Marcelo. Empresas e Direitos Humanos. Salvador: Editora Juspodivm,2018. p.67.

13 Também chamado de "local remedies rule", Nos termos dessa regra, a parte, antes de iniciar um procedimento internacional qualquer, deve esgotar anteriormente todos os recursos disponíveis no âmbito do direito interno para salvaguardar o seu direito potencialmente violado, somente podendo iniciar um procedimento internacional quando a mais alta corte de seu país houver julgado improcedente a sua demanda. Tal é a regra em sua forma clássica que, modernamente, comporta várias limitações, entre elas a de não ser utilizável quando a aplicação de tais recursos prolongar-se injustificadamente, à maneira do que autoriza o art. 5. ${ }^{\circ}$, § 2.0 , b, do próprio Protocolo. (MAZZUOLI, Valerio de Oliveira. Curso de Direitos Humanos. 6aed., atual. e ampl. Rio de Janeiro: Forense; São Paulo: Método,2019.p.111)

14 Representados pela Articulação Internacional dos Atingidos e Atingidas pela Vale, Defensoria Pública da União, Internacional de Trabalhadores da Construção e da Madeira, Movimento dos Atingidos por Barragens, Justiça Global, Justiça nos Trilhos, Rede Sindical de Barragens no Brasil e Sindicato dos Trabalhadores na Indústria de Construção Pesada de Minas Gerais.

15 http://search.oas.org/pt/paginas/default.aspx?k=mariana. Acesso em 08.09.2019

16 Relatório $\mathrm{CIDH}$, disponível em https://www.oas.org/pt/cidh/prensa/notas/2018/238.asp. Acesso em 09.09.2019. 
DE BARROS LEAL, Mayka Marques Paes. As tragédias socioambientais no brasil: a emergência da responsabilização das empresas mineradoras frente à violação dos direitos humanos. Revista Eletrônica Direito e Política, Programa de Pós-Graduação Stricto Sensu em Ciência Jurídica da UNIVALI, Itajaí, v.16, n.1, $1^{\circ}$ quadrimestre de 2021. Disponível em: www.univali.br/direitoepolitica - ISSN 1980-7791

\subsection{Caso Brumadinho e o "replay" majorado da tragédia em Mariana}

Foi com perplexidade que vimos mais uma vez um rompimento de barragem no Brasil e em Minas Gerais. Conforme as notícias foram chegando começamos a ter ideia da dimensão do que tinha ocorrido, um mar de rejeitos varreu vidas em uma velocidade incrível. Trabalhadores que confiavam sua força laborativa, a sua vida e da sua família a empresa, forma atingido rapidamente pela enxurrada de lama, enquanto estavam no refeitório e em escritórios.

Ficamos nos perguntando, como mais uma vez, tão pouco tempo depois de Mariana, foi possível vermos uma tragédia tão semelhante, no mesmo estado da federação.

Em Brumadinho as informações ao menos parecem ter sido passada de forma rápida, logo informaram como seriam dadas as informações aos familiares e tão logo informaram inclusive um valor a ser oferecido a titulo de indenização, que segundo os mesmos seriam dadas de forma extrajudicial.

Mais uma vez os alarmes sonoros não soaram, e a população somente foi avisada por mensagens particulares entre os atingidos. A Vale se manifestou dizendo que os alarmes estavam intactos, mas não soaram devido a rapidez do evento danoso, ou seja, mais uma vez foram negligentes quanto ao aviso da população.

E é esse comportamento negligente, em não ativar o sistema de alerta, o fator determinante para a dimensão tomada por essa catástrofe, que aos moldes da tragédia antecedente, terá seus efeitos danosos a se desenrolar por um longo período de tempo. As consequências da não adoção das medidas cautelares de evacuação não se limitam as vidas perdidas, pela não oportunidade do seu auto salvamento, elas atingem, também, diretamente aqueles que mesmo sem 0 aviso adequado conseguiram sobreviver. ${ }^{17}$

17 REZENDE, Elcio; SILVA, Victor Vartuli Cordeiro e. De Mariana a Brumadinho: a efetividade da responsabilidade civil ambiental para a adoção das medidas de evacuação. Revista do Direito, Santa Cruz do Sul, v. 1, n. 57, p. 160-181, ago. 2019. ISSN 1982-9957. Disponível em: <https://online.unisc.br/seer/index.php/direito/article/view/13569/8298>. Acesso em: 10 out. 2019. doi:https://doi.org/10.17058/rdunisc.v1i57.13569. 
DE BARROS LEAL, Mayka Marques Paes. As tragédias socioambientais no brasil: a emergência da responsabilização das empresas mineradoras frente à violação dos direitos humanos. Revista Eletrônica Direito e Política, Programa de Pós-Graduação Stricto Sensu em Ciência Jurídica da UNIVALI, Itajaí, v.16, n.1, $1^{\circ}$ quadrimestre de 2021. Disponível em: www.univali.br/direitoepolitica - ISSN 1980-7791

Em Brumadinho, as instituições parecem ter tomado atitudes mais rapidamente, logo foi instaurados inquéritos, houveram investigações, que resultaram inclusive cumprimento de mandado de prisões em desfavor de alguns executivos da empresa. Foi apurado também, que a empresa Vale e a empresa que atestou o segurança das barragens, sabiam de risco de rompimento, mas acordaram em mascarar tais afirmações. ${ }^{18}$

Contudo, ao olharmos o cenário, vemos um dos grandes acidentes trabalhistas da história do Brasil, vimos muitos animais mortos, por diversas formas (sufocados, por inanição, etc), vimos corpos sendo encontrados dilacerados, moradias e propriedades embaixo de lama, rastros de doe e descanso empresarial e estatal.

\subsubsection{A Inércia contínua do Brasil e da Vale que refletiram em maiores violações dos direitos humanos}

Depois que ocorrem eventos extremos que causam comoção social, geralmente medidas concretas e urgentes são anunciadas pelas autoridades, contudo após Mariana ao invés de dotar órgãos fiscalizadores com estrutura e recursos para garantir a segurança das barragens, seguiu-se a inércia e negligência governamentais.

Como vimos, em Mariana, não houve responsabilização e punição adequadas das empresas envolvidas, e até hoje pessoas não tiveram indenização adequada e o meio ambiente demorará em muito para se recuperar.

As políticas governamentais também não caminharam a fim de evitar nova tragédia e proteger vidas, um exemplo disso é que no governo de Michel Temer, publicou-se o Decreto n 9.406/2018 de 12 de junho de 2018, que, segundo o presidente, visavam tornar as empresas mineradoras mais competitivas, reduzindo multas e liberando novas áreas para a exploração. Ou seja, a tragédia

18 AGÊNCIA BRASIL. Disponível em: http://agenciabrasil.ebc.com.br/geral/noticia/2019-01/doisengenheiros-suspeitos-de-fraudes-em-brumadinho-sao-presos. Acesso em 10.09.2019. 
DE BARROS LEAL, Mayka Marques Paes. As tragédias socioambientais no brasil: a emergência da responsabilização das empresas mineradoras frente à violação dos direitos humanos. Revista Eletrônica Direito e Política, Programa de Pós-Graduação Stricto Sensu em Ciência Jurídica da UNIVALI, Itajaí, v.16, n.1, $1^{\circ}$ quadrimestre de 2021. Disponível em: www.univali.br/direitoepolitica - ISSN 1980-7791

de Mariana não fez com o que governo olhasse e agisse no intuito de evitar novas tragédias.

Desde Mariana, o País remou contra o fluxo da segurança e da prevenção e o resultado não demorou a acontecer: o rompimento de mais uma barragem de rejeitos minerários, agora em Brumadinho, na maior tragédia socioambiental com vítimas fatais da história brasileira.

Em Brumadinho, embora a Vale possuísse laudos válidos, os laudos foram feitos por empresa contratada por eles, conforme determina as leis, e com indícios de que ocorreram fraudes e adulterações na confecção destes laudos, conforme já dissemos acima.

\subsubsection{Acordos, reparações e novamente o afastamento do Princípio da centralidade do sofrimento da vítima}

Sem dúvida nenhuma o número de vítimas nos dois desastres é algo que merece atenção, principalmente porque depois do ocorrido cabe a empresa a indenização devida e justa.

Em Mariana quem foi responsável pela identificação das vitimas foi a própria empresa. Houveram inúmeras tentativas de acordos coletivos que foram frustados.

Fato é que só quem só foi atingido pela lama consegue avaliar o que pode ser e como pode ser indenizado. Não é a empresa, governo ou até mesmo membros de instituições que podem falar por elas, o sofrimento é único em cada caso. Há casos que não há só dano material, há dano no psique e/ou na moral, que exigirá tratamento longânime, outros será mais breve, etc.

Cançado Trindade quando suscitou tal principio no julgamento do caso de Villágran Moralles e outros vs. Guatemala ${ }^{19}$ disse exatamente isso, que se deve levar em

19 Sentença disponível em http://www.corteidh.or.cr/docs/casos/articulos/Seriec 63 esp.pdf. Acesso em 12 set.2019 
DE BARROS LEAL, Mayka Marques Paes. As tragédias socioambientais no brasil: a emergência da responsabilização das empresas mineradoras frente à violação dos direitos humanos. Revista Eletrônica Direito e Política, Programa de Pós-Graduação Stricto Sensu em Ciência Jurídica da UNIVALI, Itajaí, v.16, n.1, $1^{\circ}$ quadrimestre de 2021. Disponível em: www.univali.br/direitoepolitica - ISSN 1980-7791

conta a vitimização, o sofrimento humano e a reabilitação da vítima e esses elementos quem pode dar é tão somente a vítima ninguém mais pode dar voz a isso, eis o principio da centralidade do sofrimento da vítima que deve ser observado.

De acordo com esse princípio, o ser humano que sofreu as perdas e prejuízos decorrentes da ação de outro ser humano, do Estado, ou ainda de qualquer outro agente, seja pessoa natural ou jurídica, é a vítima do dano e deve figurar como o ponto central da discussão jurídica à respeito da reparação do mesmo. Além disso, o ser humano vitimado também deve participar, com centralidade, na elaboração de mecanismos, judiciais ou não, de prevenção da vitimização, para evitar que os mesmos fatos danosos voltem a acontecer e a fazer mais vítima. ${ }^{20}$

Para o autor a razão ultima do Direito Internacional dos Direitos Humanos é a proteção das vítimas, afinal ao garantir a posição central das vítimas o Direito Internacional dos Direitos Humanos contribui para a humanização do Direito como um todo, inclusive no tratamento dado pelo Estado a esses seres humanos.

O Estado parece jogar essa responsabilidade somente para o judiciário, pois poderia destacar seus assistentes sociais de forma a atuarem para emissão de relatórios de cada vítima e não deixando só ao encargo das empresas, afinal, pois o Estado também teria documentos e meios hábeis para cobrar das empresas as indenizações.

Por consequência, quando pensamos no principio da centralidade do sofrimento da vítima, devemos pensar nas indenizações do dano sofrido, esse dano deve ser pensado como um todo.

Por isso, antes mesmo de se estipular qualquer forma de reparação, a principal tarefa é identificar as vítimas do dano. Em violações como as apresentadas acima, que se dirigem contra um ou mais indivíduos certos e identificáveis de alguma maneira, a tarefa não é das mais difíceis, pois é claro que os parentes próximos e todos aqueles que mantinham laços de afetividade e alguma intimidade

20 TRINDADE, CANÇADO. Tratado de Direito Internacional dos Direitos Humanos. Porto Alegre: Sergio Antonio Fabris Editor, 2003. 3 v. 
DE BARROS LEAL, Mayka Marques Paes. As tragédias socioambientais no brasil: a emergência da responsabilização das empresas mineradoras frente à violação dos direitos humanos. Revista Eletrônica Direito e Política, Programa de Pós-Graduação Stricto Sensu em Ciência Jurídica da UNIVALI, Itajaí, v.16, n.1, $1^{\circ}$ quadrimestre de 2021. Disponível em: www.univali.br/direitoepolitica - ISSN 1980-7791

com a vítima são, sem sombra de dúvidas, vítimas indiretas do dano e titulares do direito de o verem de alguma forma reparado. ${ }^{21}$

Até o momento, no que tange as tragédias de Mariana e Brumadinho, parece que em nenhum momento foi observado tal princípio, até porque o centro de discussões parece ter sidos tomados pelas empresas, ou por representações delas, não observando em nenhuma das ações o sofrimento de cada vítima.

\section{NECESSIDADE DE RESPONSABILIZAÇÃO SOLIDÁRIA DE ESTADOS E EMPRESAS TRANSNACIONAIS E OUTRAS POSSÍVEIS SOLUÇÕES PARA MAIOR PROTEÇÃO AOS DIREITOS HUMANOS}

Até 2011 permaneceu uma narrativa jurídica internacional que estabelecia um frágil sistema de responsabilidade internacional indireta nas situações de violações de Direitos Humanos por empresas. ${ }^{22}$ Conforme já expomos acima, para o Direito Internacional, somente os Estados (aqui como Estado fiscalizador) e os indivíduos podem ser responsabilizados por essas violações aos direitos humanos. A responsabilidade das empresas não existe, mesmo em norma soft law ${ }^{23}$, exatamente por elas estarem fora de um discurso de estado de Direito Internacional, não possuindo direitos, deveres e portanto sem responsabilidade.

\footnotetext{
21 SENRA, Laura Monteiro. O Principio da centralidade do sofrimento da vítima e seus reflexos na prestação jurisdicional brasileira: Uma análise do crime de Mariana. Juiz de Fora: Homa. p 36.

22 GIANNATTASIO, Arthur Roberto Capella; NOGUEIRA, Clara Soares; BISCAIA, Bruno Simões. PIOVESAN, Flávia; SOARES, Inês Virgínia P,; TORELLY, Marcelo. Empresas e Direitos Humanos. Salvador: Editora Juspodivm,2018 p.64

23 Há quem entenda, como o jurista Andrew Clapham, que a adesão a uma norma de soft law, caracterizaria uma personalidade jurídica internacional ainda que limitada, pois diferente da atribuída a Estados ou Organizações Internacionais. Em todo caso, mesmo sujeito de direitos, não haveria responsabilização internacional das mesmas.
} 
DE BARROS LEAL, Mayka Marques Paes. As tragédias socioambientais no brasil: a emergência da responsabilização das empresas mineradoras frente à violação dos direitos humanos. Revista Eletrônica Direito e Política, Programa de Pós-Graduação Stricto Sensu em Ciência Jurídica da UNIVALI, Itajaí, v.16, n.1, $1^{\circ}$ quadrimestre de 2021. Disponível em: www.univali.br/direitoepolitica - ISSN 1980-7791

\subsection{A percepção pela ONU da necessidade de responsabilizar as empresas}

Desde $1945^{24}$ a ONU vem procedendo e inspirando legislações domésticas e adoção de políticas públicas voltadas a proteção aos direitos humanos.

Em relação a questão das empresas transnacionais as primeiras tratativas nas Nações Unidas são de 1973, momento em que as antigas colônias europeias , aos conquistarem sua independência, começavam a fazer uso de foros multilaterais, como a ONU, para buscar reverter desiquilíbrios mundiais de poder. Em 1974 houve a criação da Comissão das Nações Unidas sobre Corporações transnacionais.

Em 1977 foi criado um Grupo de Trabalho Intergovernamental, que tinha como objetivo redigir um código de conduta para as empresas transnacionais, este grupo formulou uma minuta que se tornou pública em 1984, contudo gerou diversas controvérsias que acabou sendo abandonada.

No final dos anos noventa, o debate foi reaberto, pela iniciativa da própria instituição e no ano 2000 foi lançado o Pacto Global contendo inicialmente nove princípios a serem assumidos por empresas na área de direitos humanos, trabalho e meio ambiente. Tal adesão ao pacto seria de forma voluntária pelas empresas.

\subsubsection{Proteger, respeitar e remediar: Marco Ruggie e a voluntariedade}

Como a adesão do Pacto é voluntária, algumas vezes, os signatários, acabam utilizando a adesão, como tão somente uma ferramenta de marketing não dando efetividade ao acordado. ${ }^{25}$

O que está presente nos Princípios de Ruggie é a estrutura das
regras de soft law: (i) reconhecimento de valor e alcance normativo
de caráter jurídico, mas (ii) estabelecimento de uma forma
normativa mitigada mediante (iii) ausência de previsão de
instrumentos de garantia normativa. Em outras palavras, o desenho
institucional envolvido na criação de regras de soft law não retira

24 BENEDETTI, Juliana Cardoso. Empresas e Direitos Humanos nas Nações Unidas: Rumo a um tratado? In: PIOVESAN, Flávia; SOARES, Inês Virgínia ${ }, ;$ TORELLY, Marcelo. Empresas e Direitos Humanos. Salvador: Editora Juspodivm,2018.p 20.

${ }_{25}$ No Brasil são cerca de 650 empresas que são signatárias deste acordo. 
DE BARROS LEAL, Mayka Marques Paes. As tragédias socioambientais no brasil: a emergência da responsabilização das empresas mineradoras frente à violação dos direitos humanos. Revista Eletrônica Direito e Política, Programa de Pós-Graduação Stricto Sensu em Ciência Jurídica da UNIVALI, Itajaí, v.16, n.1, $1^{\circ}$ quadrimestre de 2021. Disponível em: www.univali.br/direitoepolitica

- ISSN 1980-7791

o caráter de norma jurídica delas: ele apenas retira os mecanismo que asseguram a realização ou o cumprimento de suas normatividades. ${ }^{26}$

Ainda no meio de discussões de comissões, países, empresas e sociedade civil, em 2005 foi nomeado pelo então Secretário-Geral das Nações Unidas, o austroamericano Jonh Gerard Ruggie, que apresentou o chamado "Marco Proteger, Respeitar e Remediar sobre negócios e Direitos Humanos", que foi nomeado como Marco Ruggie.

Conforme notamos pelo nome original, o Marco estava alicerçado pelo dever do Estado de oferecer proteção contra abusos de direitos humanos cometidos por terceiros, incluindo empresas, por meio de politicas, regulação e atribuição de responsabilidades ${ }^{27}$; a reponsabilidade corporativa de respeitar os direitos humanos, atuando com a devida diligência ${ }^{28}$ para evitar infringir direitos e lidar com impactos adversos que possam advir com sua atuação ; e o acesso das vitimas à reparação efetiva judicias ou extra-judiciais.

O Marco foi aprovado por unanimidade em 2008 na ONU e juntamente com a resolução que renovou o mandado de John Ruggie, estipulou novos objetivos afim de dar maior proteção aos direitos humanos, sobretudo quando envolver empresas.

Nesse segundo mandato, |Ruggie, traçou 31 Princípios Orientadores das Nações Unidas sobre Negócios e Direitos Humanos, divididos em três seções, relativos aos princípios base de Proteger, Respeitar e Reparar/Remediar, voltados a qualquer tipo de empresa, independente de sua localização, tamanho ou titularidade. Tais Princípios foram aprovados e endossados unanimemente pelo Conselho de Direitos humanos da ONU em 2011.

26 GIANNATTASIO, Arthur Roberto Capella; NOGUEIRA, Clara Soares; BISCAIA, Bruno Simões. PIOVESAN, Limites na responsabilização internacional de empresas nos sistemas regionais de Direitos Humanos: o aprendizado institucional como alternativa. in Flávia; SOARES, Inês Virgínia P, ; TORELLY, Marcelo. Empresas e Direitos Humanos. p.55.

27 Chamado de adjucation

${ }^{28}$ Chamado de Due diligence 
DE BARROS LEAL, Mayka Marques Paes. As tragédias socioambientais no brasil: a emergência da responsabilização das empresas mineradoras frente à violação dos direitos humanos. Revista Eletrônica Direito e Política, Programa de Pós-Graduação Stricto Sensu em Ciência Jurídica da UNIVALI, Itajaí, v.16, n.1, $1^{\circ}$ quadrimestre de 2021. Disponível em: www.univali.br/direitoepolitica - ISSN 1980-7791

Contudo, para muitos especialistas, tais princípios, não atenderiam a proteção aos direitos humanos de forma aceitável e factível.

Ao pôr em prática seu 'liberalismo enraizado', Ruggie deixou de levar em conta o pleito da sociedade civil pela elaboração de um instrumento de caráter vinculante com supervisão internacional, reivindicando motivada fragilidade dos instrumentos baseados na adesão voluntária e no automonitoramento ${ }^{29}$.

Ainda, acredita-se que Ruggie também não levou em conta a vunerabilidade de países em desenvolvimento frente a empresas violadoras, os Princípios, silenciam sobre a responsabilidade dos países de origem dessas empresas. ${ }^{30}$

Fato é, que a Vale S/A, envolvidas nas tragédias socioambientais brasileira de Mariana e Brumadinho, era signatária do Pacto Global, voluntária, e após a tragédia de Brumadinho cedendo as pressões de sociedade civis organizadas, resolveu sair do Pacto sem receber qualquer tipo de sanção pelas tragédias.

\subsubsection{Mobilização da ONU para elaboração de um tratado}

Valério Mazzuoli, faz um apontamento muito interessante sobre os Princípios Ruggie e a necessidade de que haja um tratado, vejamos:

os Princípios Ruggie não avançaram como deveriam na missão de impor normas mais rígidas sobre responsabilidade empresarial e, tampouco, no que toca à sensibilização dos atores estatais para o acompanhamento e fiscalização mais presentes das atividades de grandes empresas. Faltante, portanto, o voluntarismo de Estados e empresas em observar as diretrizes das Nações Unidas, resta evidentemente prejudicada qualquer tentativa de responsabilização internacional decorrente de sua não observância, razão pela qual fazse premente negociar verdadeiro tratado (hard law) sobre responsabilidade dos Estados e empresas por violação a direitos humanos. Havendo tratado (futuro) sobre o tema, os Princípios Orientadores da ONU poderiam complementá-lo a título de guia

29 BENEDETTI, Juliana Cardoso. Empresas e Direitos humanos nas Naçõs unidades: rumo a um tratado? in Flávia; SOARES, Inês Virgínia P,; TORELLY, Marcelo. Empresas e Direitos Humanos. p.29.

${ }^{30}$ BENEDETTI, Juliana Cardoso. Empresas e Direitos humanos nas Naçõs unidades: rumo a um tratado? in Flávia; SOARES, Inês Virgínia P,; TORELLY, Marcelo. Empresas e Direitos Humanos. p 31 . 
DE BARROS LEAL, Mayka Marques Paes. As tragédias socioambientais no brasil: a emergência da responsabilização das empresas mineradoras frente à violação dos direitos humanos. Revista Eletrônica Direito e Política, Programa de Pós-Graduação Stricto Sensu em Ciência Jurídica da UNIVALI, Itajaí, v.16, n.1, $1^{\circ}$ quadrimestre de 2021. Disponível em: www.univali.br/direitoepolitica - ISSN 1980-7791

interpretativo, bem assim servir para colmatar suas eventuais lacunas. ${ }^{31}$

Este pleito para que haja uma norma vinculante, hard law, é tão forte que em 2014, por meio da Resolução 26/9 foi estabelecido um grupo de Trabalho Intergovernamental de Composição aberta de sigla OEIWG com um mandato para elaborar um instrumento jurídico vinculante, e na resolução decidiram que as duas primeiras sessões não teriam caráter negociador e sim seria deliberações construtivas.

A primeira reunião foi em 2015, com várias discussões cerca da presidência e da definição do programa de trabalho da sessão que suscitou controvérsias. A União Europeia manifestou o desejo que o tratado valesse para todas as empresas independente de ser ou não transnacionais. A União Europeia em protesto se retirou do grupo de trabalho.

Houveram algumas desistências, contudo os trabalhos seguiram e em 2016, na segunda sessão, com número de participação maior, avanços ocorreram.

A reunião promoveu intercambio profícuo sobre as iniciativas já existentes que poderão subsidiar a elaboração do futuro tratado, especialmente sobre instrumentos que já admitem empresas como sujeitos de deveres, como a Convenção-Quadro sobre o Controle do Tabaco e Convenção de Montego Bay sobre o Direito do Mar. Também inclui debate sobre medidas legais que poderiam facilitar a responsabilização de empresas e acesso de vítimas à reparação por abusos, como a desconsideração da personalidade jurídica das empresas para permitir a responsabilização civil e criminal de indivíduos ('lifiting the coporate veil'), a inversão do ônus da prova em favor das vítimas e a admissão de modalidades de extraterritorialidade. ${ }^{32}$

Entendemos que esse tratado deve garantir, no mínimo, a primazia dos direitos humanos e do meio ambiente sobre as normas de comércio e de investimento, bem como fazer com que as empresas e seus dirigentes sejam responsabilizados

\footnotetext{
31 MAZZUOLI, Valerio de Oliveira. Curso de Direitos Humanos. 6.ed., atual. e ampl. Rio de Janeiro: Forense; São Paulo: Método,2019. p 560-561

32 MAZZUOLI, Valerio de Oliveira. Curso de Direitos Humanos. p. 35
} 
DE BARROS LEAL, Mayka Marques Paes. As tragédias socioambientais no brasil: a emergência da responsabilização das empresas mineradoras frente à violação dos direitos humanos. Revista Eletrônica Direito e Política, Programa de Pós-Graduação Stricto Sensu em Ciência Jurídica da UNIVALI, Itajaí, v.16, n.1, $1^{\circ}$ quadrimestre de 2021. Disponível em: www.univali.br/direitoepolitica - ISSN 1980-7791

por violações aos direitos humanos diretamente ou indiretamente ligados a suas atividades.ao longo de toda a cadeia de valor.

\title{
2.2 - Responsabilidade Solidária: Estado e empresas promovendo os direitos humanos
}

Os Estados são os principais obrigados para com o Direito Internacional dos Direitos Humanos e, por isso, podem (devem) ser responsabilizados por sua violação. ${ }^{33}$ Essa obrigação dada aos Estados tem duas finalidades: a preventiva, que visa a coerção psicológica aos Estado e a repressiva, que visa a reparação do dano ao sujeito prejudicado. ${ }^{34}$

A responsabilidade internacional tem relação com a ideia de justiça, é o que ensina Mazzuoli:

\begin{abstract}
O princípio fundamental da responsabilidade internacional traduz-se numa ideia de justiça segundo a qual os Estados estão vinculados ao cumprimento daquilo que assumiram no cenário internacional, devendo observar seus compromissos de boa-fé e sem qualquer prejuízo aos outros sujeitos do direito das gentes e às pessoas sujeitas a sua jurisdição. ${ }^{35}$
\end{abstract}

Diante do exposto, vemos que a responsabilidade internacional tem funções de prevenção e repreensão e é pautada na ideia de justiça. Nesse sentido, pensamos, que não seria difícil imputar as empresas, sobretudo as transnacionais, a responsabilidade internacional e seus efeitos.

Para tanto é necessário que nos afastemos da ideia de um Estado estatocêntrico, centralizado, onde tudo, e inclusive punições devam ser dados somente ao Estado. Isso se da também pela necessidade de colocarmos os direitos humanos acima de qualquer norma ou limitação.

\footnotetext{
33 MAZZUOLI, Valerio de Oliveira. Curso de Direitos Humanos.p 39.

34 MAZZUOLI, Valerio de Oliveira. Curso de Direitos Humanos.p 40.

35 MAZZUOLI, Valerio de Oliveira. Curso de Direitos Humanos.p.41.
} 
DE BARROS LEAL, Mayka Marques Paes. As tragédias socioambientais no brasil: a emergência da responsabilização das empresas mineradoras frente à violação dos direitos humanos. Revista Eletrônica Direito e Política, Programa de Pós-Graduação Stricto Sensu em Ciência Jurídica da UNIVALI, Itajaí, v.16, n.1, $1^{\circ}$ quadrimestre de 2021. Disponível em: www.univali.br/direitoepolitica - ISSN 1980-7791

\subsubsection{A necessidade de superação do paradigma estatocêntrico}

A corte Interamericana de Direitos humanos tem entendido que como o direitos humanos tem caráter erga homens partes e erga omnes latu sensu, geram efeitos também para terceiros. Em suas opiniões consultivas, como a OP 18/03 a Corte Interamericana de Direitos Humanos expressamente entendeu que a obrigação de respeito e garantia aos direitos humanos gera efeitos não somente na relação clássica entre Estado e indivíduos submetidos à sua jurisdição, como também projeta efeitos nas relações entre indivíduos. Contudo lembramos, que na estrutura do Sistema Interamericano ainda só o Estados respondem.

Cançado Trindade em seu voto, como sempre, aprofundou a discussões e entendeu que há duas dimensões a horizontal e a vertical. A horizontal diz respeito a obrigação de proteção aos direitos humanos pela comunidade internacional, e vinculam os Estados partes em tratados e na dimensão vertical as obrigações vinculam os agentes do poder estatal e os particulares nas relações individuais, nas quais incluiriam as empresas.

No mesmo voto, Cançado Trindade, esclarece que não há que se diminuir as obrigações erga omnes partes e sim uma possível ampliação para uma possível obrigação erga omnes latu sensu, reforçando, inclusive, a necessidade de se reconhecer da Convenção Americana de direitos humanos em relação a terceiros, diante das inúmeras fontes de violações de direitos humanos.

\subsubsection{A proteção aos direitos humanos como Grundnorm em toda a cadeia produtiva}

É necessário que as cadeias de valor se enquadrem à lógica da chamada Human Rights Due Diligence ${ }^{36}$ e busquem meios de responsabilização aplicáveis a todo o sistema de produção, desde a matriz até as subsidiárias e fornecedores, estabelecendo um sistema no qual a empresa matriz seja obrigada a monitorar a atuação das demais companhias parte de seu processo produtivo.

\footnotetext{
${ }^{36}$ Cujo conceito define que as empresas são capazes de verificar o potencial lesivo de sua atividade e prevenir consequências graves.
} 
DE BARROS LEAL, Mayka Marques Paes. As tragédias socioambientais no brasil: a emergência da responsabilização das empresas mineradoras frente à violação dos direitos humanos. Revista Eletrônica Direito e Política, Programa de Pós-Graduação Stricto Sensu em Ciência Jurídica da UNIVALI, Itajaí, v.16, n.1, $1^{\circ}$ quadrimestre de 2021. Disponível em: www.univali.br/direitoepolitica - ISSN 1980-7791

O instrumento lógico parece ser uma saída mais confiável para resolver a questão da impunidade de corporações transnacionais e para que a devida diligência não seja restrita apenas aos países das matrizes, protegendo assim todos os envolvidos na produção, mesmo aqueles cujas leis pátrias em matéria ambiental e trabalhista são mais flexíveis.

A descaracterização do instrumento como uma iniciativa de exclusiva responsabilidade e discricionariedade das empresas, uma vez que não será autorregulada, constitui importante mudança de paradigma na busca pela superação da prevalência da lex mercatoria sobre os Direitos Humanos. Observase, portanto, a importância da institucionalização da human rights due diligence como uma obrigação das empresas. ${ }^{37}$

Trazer a proteção aos direitos humanos, como uma grande norma, uma supranorma, em toda a cadeia produtiva, deve ser um dos focos na elaboração de um tratado, conforme dissemos acima, e assim obrigar as empresas e toda a cadeia produtiva a ter os direitos humanos como uma grundnorm e assim quem sabe mudar estruturalmente as empresas.

\section{CONSIDERAÇÕES FINAIS}

Assim como as empresas podem promover direitos humanos, podem ser agentes violadores desses direitos (conforme ficou demonstrado nos desastres de Mariana e Brumadinho), tal como o Estado.

As empresas podem buscar, independentemente de sua atividade econômica, impactar positivamente ou negativamente o meio ambiente e a sociedade e logicamente pode haver rigor legal, fiscalização e incentivos por parte do Estado afim de buscar essa promoção e proteção de tais direitos.

37 ROLAND, Manoela C., SOARES, Andressa O., BREGA, Gabriel R., OLIVEIRA, Lucas de S., CARVALHO, Maria Fernanda C. G., ROCHA, Renata P. Cadeias de Valor e os impactos na responsabilização das empresas por violações de Direitos Humanos. In. Cadernos de Pesquisa Homa. vol. 1, n. 5, 2018. 
DE BARROS LEAL, Mayka Marques Paes. As tragédias socioambientais no brasil: a emergência da responsabilização das empresas mineradoras frente à violação dos direitos humanos. Revista Eletrônica Direito e Política, Programa de Pós-Graduação Stricto Sensu em Ciência Jurídica da UNIVALI, Itajaí, v.16, n.1, $1^{\circ}$ quadrimestre de 2021. Disponível em: www.univali.br/direitoepolitica

- ISSN 1980-7791

Fortalecer a responsabilidade das empresas em matéria de direitos humanos invoca a emergência de um novo paradigma capaz de transitar de uma agenda empresarial centrada exclusivamente na produtividade econômica para uma agenda ampliada e impactada pelos direitos humanos. Aponta, ainda, a uma cultura corporativa reinventada em que os direitos humanos convertem-se gradativamente em relevante componente identitário de uma nova cultura empresarial, na busca de um desenvolvimento sustentável nas esferas social, econômica e ambiental, inspirado pelo enfoque de direitos humanos- o human rigths approach. ${ }^{38}$

Sem duvida o Marco Ruggie, tentou, que se reinventasse uma nova cultura empresarial, que as empresas se empenhassem na promoção dos direitos humanos e evitassem ao máximo suas violações, todavia, parece a que a voluntariedade, adesões, não possuem forças necessária para efetivação. Tanto é que a Vale, era signatária, de tal pacto, e mesmo assim, parece, que não observou os direitos humanos em Mariana, e mesmo após o desastre, continuou a se recusar ao olhar para o humano, que acabou culminando com outra tragédia como a de Brumadinho.

Isso nos leva a crer que a punição quando consequências decorrentes de omissão ou violações aos direitos humanos, não deve recair só ao Estado, mas, também, solidariamente, as empresas que diretamente forem responsáveis por tais violações, e aqui, não estamos falando somente em punições internas, por meios de indenizações e multas, mas de punição, rigor legal, internacional, afinal em um mundo globalizado, onde empresas estão pulverizadas no mundo e o resultado de suas violações também afetam todos que habitam nesse mundo é ilógico que essas empresas cujo capital por vezes é maior que o PIB dos países que estão instaladas não sejam responsabilizadas internacionalmente.

\footnotetext{
38 PIOVESAN, Flávia; GONZAGA, Victoriana Leonora Corte. Empresas e Direitos Humanos: desafios e perspectivas à luz do Direito Internacional dos Direitos Humanos. In: PIOVESAN, Flávia; SOARES, Inês Virgínia P,; TORELLY, Marcelo (org). Empresas e Direitos Humanos.
} 
DE BARROS LEAL, Mayka Marques Paes. As tragédias socioambientais no brasil: a emergência da responsabilização das empresas mineradoras frente à violação dos direitos humanos. Revista Eletrônica Direito e Política, Programa de Pós-Graduação Stricto Sensu em Ciência Jurídica da UNIVALI, Itajaí, v.16, n.1, $1^{\circ}$ quadrimestre de 2021. Disponível em: www.univali.br/direitoepolitica - ISSN 1980-7791

Entendemos, portanto, que um tratado deve ser elaborado, afim de definir regras de fiscalização e punição, colocando a proteção aos direitos humanos e meio ambiente como Grundnorm que devem ser seguidos também pelas empresas.

\section{REFERÊNCIAS BIBLIOGRÁFICAS}

ALVES PEREIRA, Antônio Celso. ANTÔNIO AUGUSTO CANÇADO TRINDADE E A HUMANIZAÇÃO DO DIREITO BRASILEIRO.Revista do Instituto Brasileiro de Direitos Humanos, [S.I.], n. 12, p. 59-70, dez. 2012. ISSN 1677-1419. Disponível em: <http://revista.ibdh.org.br/index.php/ibdh/article/view/204> . Acesso em: 09 jun. 2019.

AZUMA, João Carlos. O Pacto Global das Nações Unidas: uma via para a responsabilidade das empresas na concretização dos direitos humanos. 2014. 165 f. Tese (Doutorado) - Curso de Direito, Efetividade do Direito, Pontifícia Universidade Católica de São Paulo, São Paulo, 2014.

BRASIL. Ministério da Saúde. Instituto Nacional de Câncer José Alencar Gomes da Silva. Convenção-Quadro para o Controle do Tabaco. Secretaria Executiva da Comissão Nacional para Implementação da Convenção-Quadro para o Controle do Tabaco; Coordenação de Elaboração Tânia Cavalcante. Rio de Janeiro: Inca, 2012. $58 \mathrm{p}$.

BENEDETTI, Juliana Cardoso. Empresas e Direitos Humanos nas Nações Unidas: Rumo a um tratado? In: PIOVESAN, Flávia; SOARES, Inês Virgínia P,; TORELLY, Marcelo. Empresas e Direitos Humanos. Salvador: Editora Juspodivm,2018. p.19-37.

BILCHITZ, David. O marco Ruggie: uma proposta adequada para as obrigações de direitos humanos das empresas?. Sur - Revista Internacional de Direitos Humanos, Itapetininga, v. 7, n. 12, p.209-241, jun. 2010

CARDIA, Ana Cláudia Ruy. Direitos humanos e empresas no Brasil: como as empresas mineradoras têm afetado a proteção dos direitos humanos no território brasileiro. Homa Publica: International Journal On Human Rights And Business, Juiz de Fora, v. 02, n. 01, p.109-137, jan. 2018. Semestral.

CALDAS, Graças (org.) Vozes e silenciamentos em Mariana: crime ou desastre ambiental. 2.ed. Campinas: Unicamp,2017.

CONECTAS. Solicitação de audiência temática: Afetações aos Direitos Humanos devido à Mineração no Brasil. 2016. Disponível em: <http://www.conectas.org/arquivos/editor/files/informe_audiência-mineração revisado.pdf>. Acesso em: 08 jun 2019. 
DE BARROS LEAL, Mayka Marques Paes. As tragédias socioambientais no brasil: a emergência da responsabilização das empresas mineradoras frente à violação dos direitos humanos. Revista Eletrônica Direito e Política, Programa de Pós-Graduação Stricto Sensu em Ciência Jurídica da UNIVALI, Itajaí, v.16, n.1, $1^{\circ}$ quadrimestre de 2021. Disponível em: www.univali.br/direitoepolitica - ISSN 1980-7791

CORTE INTERAMERICANA DE DIREITOS HUMANOS. Voto Separado de Antônio Augusto Cançado Trindade no caso "Meninos de Rua" (Villagrán Morales e outros vs. Guatemala). Reparações e custas. Julgamento de 26 de maio de 2001.

FACHIM, Milena Giradi; BOLZANI, Giulia Fontana. Eficácia horizontal dos Direitos Humanos no marco do constitucionalismo global: Responsabilidade das empresas na promoção dos Direitos. In: PIOVESAN, Flávia; SOARES, Inês Virgínia $P_{\text {, }}$; TORELLY, Marcelo. Empresas e Direitos Humanos. Salvador: Editora Juspodivm,2018. p.209-225.

GIANNATTASIO, Arthur Roberto Capella; NOGUEIRA, Clara Soares; BISCAIA, Bruno Simões. PIOVESAN, Flávia; SOARES, Inês Virgínia P,; TORELLY, Marcelo. Empresas e Direitos Humanos. Salvador: Editora Juspodivm,2018. p.53-82.

LESSA, Rafaela R. Zauli; REIS, Daniela Muradas. A ONU e a responsabilidade internacional de empresas por transgressão aos Direitos Humanos. RIDH, Bauru, v. 05, n. 02, p.261-274, dez. 2017.

MAZZUOLI, Valerio de Oliveira. Curso de Direitos Humanos. 6aed., atual. e ampl. Rio de Janeiro: Forense; São Paulo: Método,2019.

Curso de Direito Internacional Público. $11^{\text {aed. }}$, atual. e ampl. Rio de Janeiro: Forense, 2018.

Direitos Humanos na Jurisprudência Internacional: sentenças, opiniões consultivas e relatórios internacionais. Rio de Janeiro: Forense; São Paulo: Método,2019.

MILANEZ, Bruno; PINTO, Raquel Giffoni. Considerações sobre o Termo de Transação e de Ajustamento de Conduta firmado entre Governo Federal, Governo do Estado de Minas Gerais, Governo do Estado do Espírito Santo, Samarco Mineração S.A., Vale S. A. e BHP Billiton Brasil LTDA. Juiz de Fora: Poemas, 2016. Disponível em: <http://www.ufjf.br/poemas/files/2014/07/PoEMAS-2016Comentários-Acordo-Samarco.pdf>. Acesso em: 27 jun 2019.

; LOSEKANN, Cristina (org.). Desastre no Vale do Rio Doce: antecedentes, impactos e ações sobre a destruição. Rio de Janeiro: Folio Digital: Letra e Imagem, 2016.

PASSARINHO, Nathalia. Tragédia com barragem da Vale pode ser a pior do mundo em três décadas. BBC News Brasil. Disponível em <https://www.bbc.com/portuguese/brasil-47034499>. Acesso em : 05. Jun. 2019.

PORTILLA, Diana María Molina. Sistema interamericano, empresas transnacionales mineras y estados de origen: improcedencia de la excepción de falta de jurisdicción entre estados miembros. International Law: Revista Colombiana de Derecho Internacional, [s.I.], v. 14, n. 29, p.57-91, 27 abr. 2017. Editorial Pontificia Universidad Javeriana. 
DE BARROS LEAL, Mayka Marques Paes. As tragédias socioambientais no brasil: a emergência da responsabilização das empresas mineradoras frente à violação dos direitos humanos. Revista Eletrônica Direito e Política, Programa de Pós-Graduação Stricto Sensu em Ciência Jurídica da UNIVALI, Itajaí, v.16, n.1, $1^{\circ}$ quadrimestre de 2021. Disponível em: www.univali.br/direitoepolitica - ISSN 1980-7791

REZENDE, Elcio; SILVA, Victor Vartuli Cordeiro e. De Mariana a Brumadinho: a efetividade da responsabilidade civil ambiental para a adoção das medidas de evacuação. Revista do Direito, Santa Cruz do Sul, v. 1, n. 57, p. 160-181, ago. 2019. ISSN 1982-9957. Disponível em: <https://online.unisc.br/seer/index.php/direito/article/view/13569/8298>.

Acesso em: 10 out. 2019.

ROLAND, Manoela C., SOARES, Andressa O., BREGA, Gabriel R., OLIVEIRA, Lucas de S., CARVALHO, Maria Fernanda C. G., ROCHA, Renata P. Cadeias de Valor e os impactos na responsabilização das empresas por violações de Direitos Humanos. In. Cadernos de Pesquisa Homa. vol. 1, n. 5, 2018.

SALDANHA, Jânia Maria Lopes; BOHR, Clara Rossatto. Dupla influência e dupla projeção entre global e local: o "caso Mariana" e a (ir)responsabilidade social das empresas de mineração. Homa Publica: International Journal On Human Rights And Business, Juiz de Fora, v. 2, n. 2, p.156-203, jul. 2018.

SANTOS, Mariana Lucena Sousa; RIBEIRO, Cristina Figueiredo Terezo. Reflexões teóricas acerca da caracterização da responsabilidade internacional de empresas transnacionais por violações de Direitos humanos. Revista de Direitos Humanos em Perspectiva, Curitiba, v. 2, n. 2, p.162-174, jul/dez. 2016.

SENRA, Laura Monteiro. O Principio da centralidade do sofrimento da vítima e seus reflexos na prestação jurisdicional brasileira: Uma análise do crime de Mariana. Juiz de Fora: Homa.

STIVAL, Mariane Morato; SILVA, Sandro Dutra e. O desastre da barragem de mineração em Mariana e os impactos no Direito Internacional Ambiental e no brasileiro. Revista Direito Ambiental e Sociedade, Caxias do Sul, v. 8, n. 2, p.205-228, jan. 2018.

TRINDADE, Antônio Augusto Cançado. Tratado de Direito Internacional dos Direitos Humanos. Porto Alegre: Sergio Antonio Fabris Editor, 2003. 3 v.

YARZA, Fernando Simón. Medio ambiente y derechos fundamentales. Madrid: Tribunal Constitucional y Centro de Estudios Políticos y Constitucionales, 2012.

ZIERO, Gabriel Webber. O conceito de conduta empresarial responsável à luz dos ordenamentos jurídicos brasileiro, internacional e transnacional. Revista de Direito Internacional, Brasília, v. 13, n. 3, 2016 p. 80-94.

RECEBIDO EM: MAR/2020

APROVADO EM: JUL/2020 